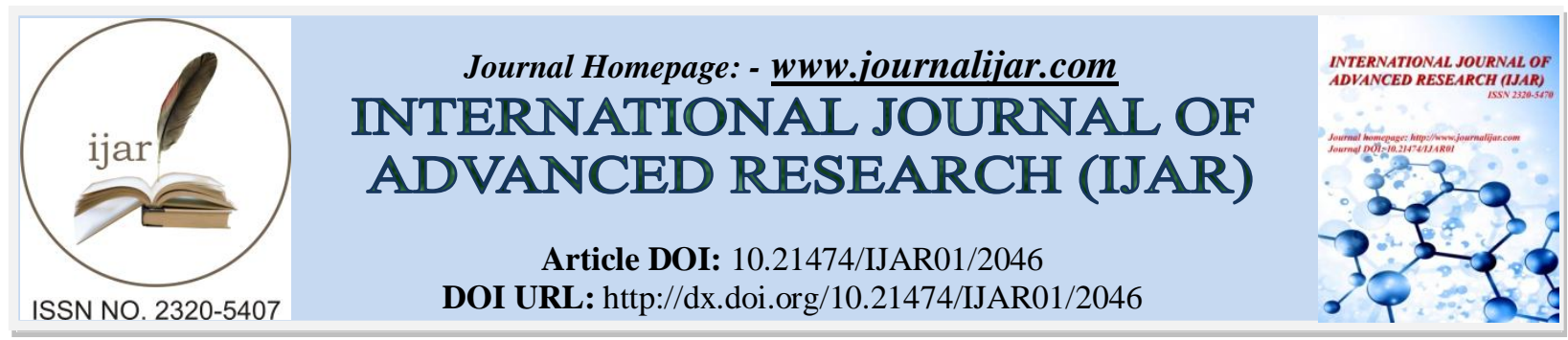

RESEARCH ARTICLE

\title{
Sensitive determination of Lead in Brine water by Cloud Point Extraction-Flame Atomic Absorption Spectrometry Method using Mixed Matrix modifying agents.
}

Nadhum A. N. Award and Bassam A. R. Alabdul Aziz.

University of Basra collage of science chemistry department. Basrah, Iraq.

\section{Manuscript Info}

Manuscript History

Received: 27 September 2016

Final Accepted: 15 October 2016

Published: October 2016

\begin{abstract}
A cloud point extraction (CPE) method was developed for the separation and preconcentration of trace amounts of lead is combined with flame atomic absorption spectrometry (FAAS) to determine trace amounts of lead in brine water. The method is depended on the formation of the hydrophobic complex between $\mathrm{Pb}$ (II) and (APDC) followed by its extraction into a Triton X-114 using surfactant. The parameters such as $\mathrm{pH}$ of sample, concentrations of APDC and Triton $\mathrm{X}-114$, equilibrium temperature, and equilibrium time, which affect both complexation and extraction, are optimized. Under the selected optimum conditions, and use of matrix modifying agents enable us to develop the direct method for determination $\mathrm{Pb}$ in brine water. The accuracy of the method was \% (96)while the detection limit was found to be $(0.1122 \mathrm{ppm})$ for preconcentration of $1.0 \mathrm{ml}$ sample,for the determination of $\mathrm{Pb}(\mathrm{II})$ is obtained.
\end{abstract}

Copy Right, IJAR, 2016,. All rights reserved.

\section{Introduction:-}

Inorganic lead arising from a number of industrial and mining sources occurs in water in the +2 oxidation state.[1].Short-term exposure to high levels of lead can cause vomiting, diarrhea, convulsions, Coma or even death. However, partial contact to even very small amounts of lead can be hazardous, especially to infants and young children. Therefore it is very significant to examine the trace levels of it in environments[2].Presently, the mostcommon analytical methods for the determination of trace amount of lead are the flame atomic absorption spectrometry (FAAS) [3]. The electrothermal atomic absorption spectrometry (ETAAS) [4] and the inductively coupled plasma emission spectrometry (ICP) [5]. Flame atomic absorption spectrometry is by far the most commonly employed technique for analyte determination[6].

Principles of CPE have been mentioned in some interesting reviews [7]. Non-ionic surfactants in aqueous solutions have an affinity to form micelles and become turbid at a certain temperature, which is called "cloud point temperature." Exceeding the temperature, the micellar solution separates into two phases: a surfactant-rich phase of a small volume and a dilute aqueous phase [8]. While metal ions react with a suitable ligand and form an aqueous low solubility complex, they can be extracted from the aqueous solution into the small-volume surfactant-rich phase. This method is an uncomplicated experimental process with, environmental safety, not expensive, high ability for preconcentration of broad variety of analytes, and high improvement factor with good recoveries [9]. In present of 
these advantages, cloud point extraction and name atomic absorption have been united together to determine a variety of metal ions in an environmental samples [10],[11].

Cloud point extraction and atomic absorption spectrometry have been effectively employed for a number of elements in different matrices and it is an interesting option when a complex matrix has to be analyzed [12], [13], [14]. Cloud point extraction CPE complex has become an important branch for the separation and preconcentration of trace metal ions [15],[16]. In this research work CPE combine with matrix modyfing agent enables to a simple sensitive, and accurate method for separation and preconcentration for the determination of $\mathrm{Pb}^{+2}$ ions in brine water and waste water using APDC as selective and sensitive complexing agents in basic media was established.

\section{Material and Method:- \\ Reagents and solutions:-}

All solutions were prepared with distilled water, analytical grade used in this study were obtained from international companies and used as received without more purification. The calibration curve for $\mathrm{Pb}^{+2}$ ions was established using standard solutions prepared at optimum conditions for each ion. $\mathrm{Pb}\left(\mathrm{NO}_{3}\right)_{2}$ in purity $99.99 \%$ from (B.H.D), Triton-X114 purity Analer from (B.H.D).

\section{Apparatus:-}

Shimadzu AA-630-12 Atomic Absorption /Flame Emision spectrophotometer (Japan),pH- meter Adwa AD 1030, Heraeus SEPATECH Labofuge 200 Centerfuge,Thermostatic water Bath.Model YCW-01, Shaker model KA 500Kika-WERK, Electronic balance model AE ADAM, BWB Flame Emission Spectrophotometer.

\section{Procedure:-}

For the cloud point extraction, an aliquots $1 \mathrm{ml}$ of a solution containing lead, are mixed with $0.6 \mathrm{ml}$ of $1 \mathrm{~N} \mathrm{HNO}_{3}, 2$ $\mathrm{ml}$ Triton X-114 1\% (W/V) and $2.5 \mathrm{ml}$ of 200 ppmAPDC. The mixture were placed in a volumetric flask, the mixture (1:1) volume ratio of $2 \mathrm{ml}$ Hydroznium sulphat:Amonium nitrite was add and the volume completed by DW, the total amount was transfer to centrifuge tube and heated in a thermostat water bath at $45^{\circ} \mathrm{C}$ for 20 min.

After heated, the resultant solution was subjected to centrifugation at $3500 \mathrm{rpm}$ for $10 \mathrm{~min}$ for phase separation, and then cooled in an ice-water for 10 mint in order to increase the viscosity of the surfactant-rich phase. The supernatant aqueous phase was easily decanted by simple decantation. To decrease the viscosity of the surfactant phase and aspiration in flame, $0.5 \mathrm{ml}$ of ethanol and 2 drops of $1 \mathrm{~N} \mathrm{HNO}_{3}$ was added. And mixed well. The resultant solution was introduced into flame by conventional aspiration.

\section{Applications:-}

A real water sample from river, sea,waste water and discharge reverse osmosis plant has been used in this work.

\section{Water samples:-}

Water samples were collected from certain sampling area(southern shat al arab,Faw,Basrah wast water treatment and revers osmoses discharge water ). They were filtered through Watman filter paper No. 42 and stored in a glass bottles at $4^{\circ} \mathrm{C}$. Then the samples were ready for analysis.

\section{Results and Discussion:-}

For removal of matrix effect and to attain the best performance for the cloud point extraction procedure,the parameters such as $\mathrm{pH}$ of sample, concentrations of APDC and Triton X-114. Effects of the using of matrix modyfing dilution agent for the surfactant-rich phase equilibrium temperature, and equilibrium time, which affect both complexation and extraction, are optimized. Under the selected optimum conditions, the preconcentration of $1 \mathrm{~mL}$, for the determination of $\mathrm{Pb}^{+2}$ ions is obtained.

\section{Effects of matrix modifying agent:-}

Brine water with (Salinity 2.7-40\%) is a complex matrix. Therefore, there is high matrix effect on the resonance line of $\mathrm{Pb}$ element at $217 \mathrm{~nm}$. Therefore, the secondary line $283.1 \mathrm{~nm}$ was had been used $\mathrm{Pb}$ analysis. Additionally, a matrix modifying agent(hydozonium sulphate $1 \%$ M1and ammonium nitrate $1 \% \mathrm{M} 2$ ) was used to overcome the interference. Absorbance of $0.5 \mathrm{ppm}$ of lead was studied in the presence of $1 \mathrm{ml}$ matrix (sample) and matrix modifying agents. The result shows the enhancement of lead signal absorbance. (Figure 1). Mixing modifying agents with different ratio was examined as shown in (Figure 2). Diluting by 1:1 mixing modifying agents was chosen for further works. 


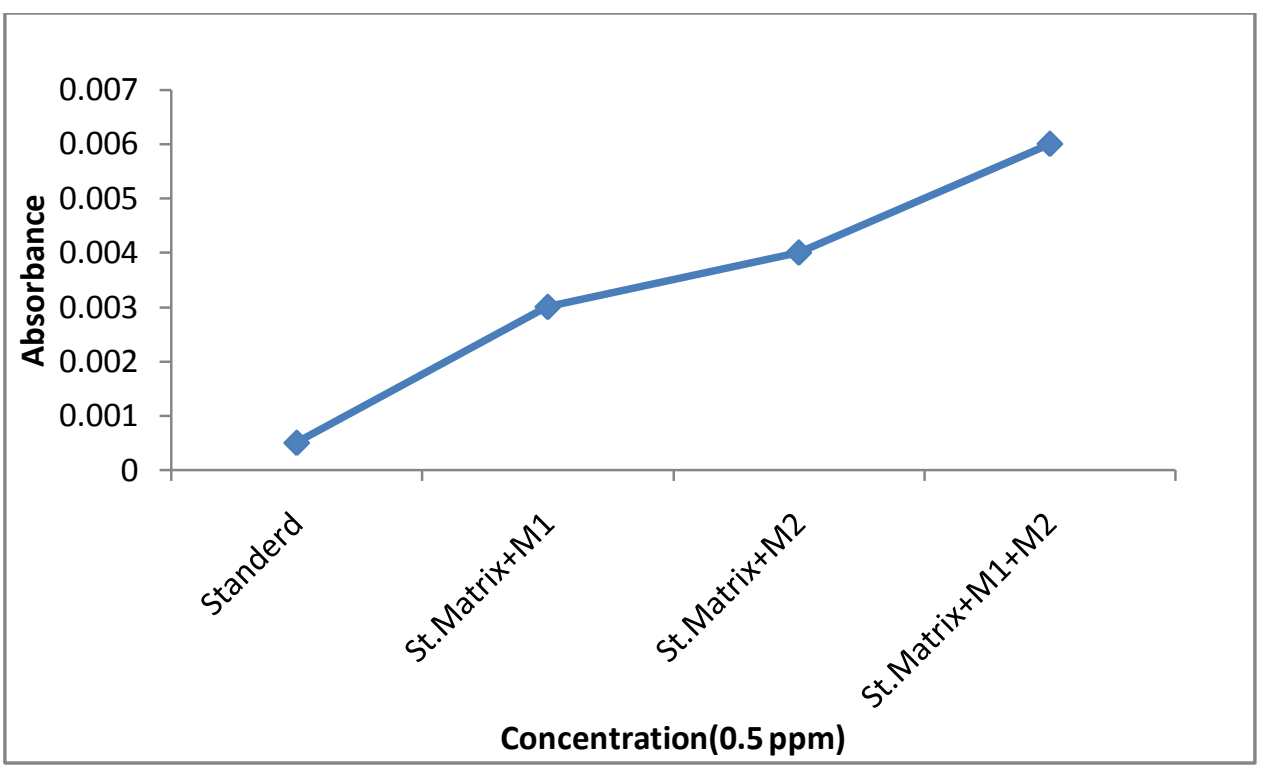

Figure 1 Effect of different modifying agents and mixed modifying agent on $\mathrm{Pb}$ atomic absorption signal.

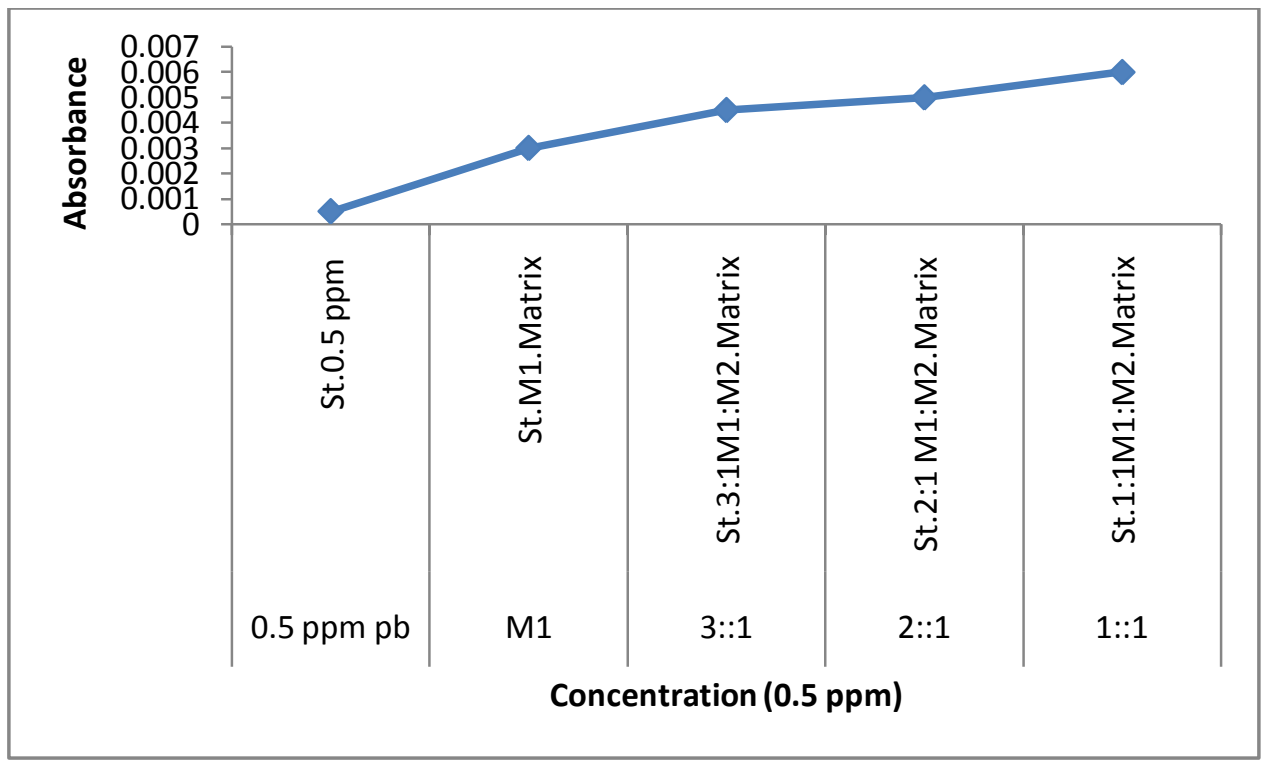

Figure 2 Effect of mixed modifiers of different proportions on the signal of $0.5 \mathrm{ppm} \mathrm{Pb}$

\section{Effect of pH:-}

Optimization of $\mathrm{pH}$ plays an exclusive role on metal-chelate formation and subsequent extraction, and is proved to be a major parameter for $\mathrm{CPE}$. The influences of $\mathrm{pH}$ of the aqueous solutions on yield the extraction of $\mathrm{Pb}$ (II) as APDC chelate was investigated in the $\mathrm{pH}$ range 1-5 using nitric acid and its found the rang of $\mathrm{pH}$ between (1.8-2.5) shows the enhancement of lead signal absorbance (Figure 3). 


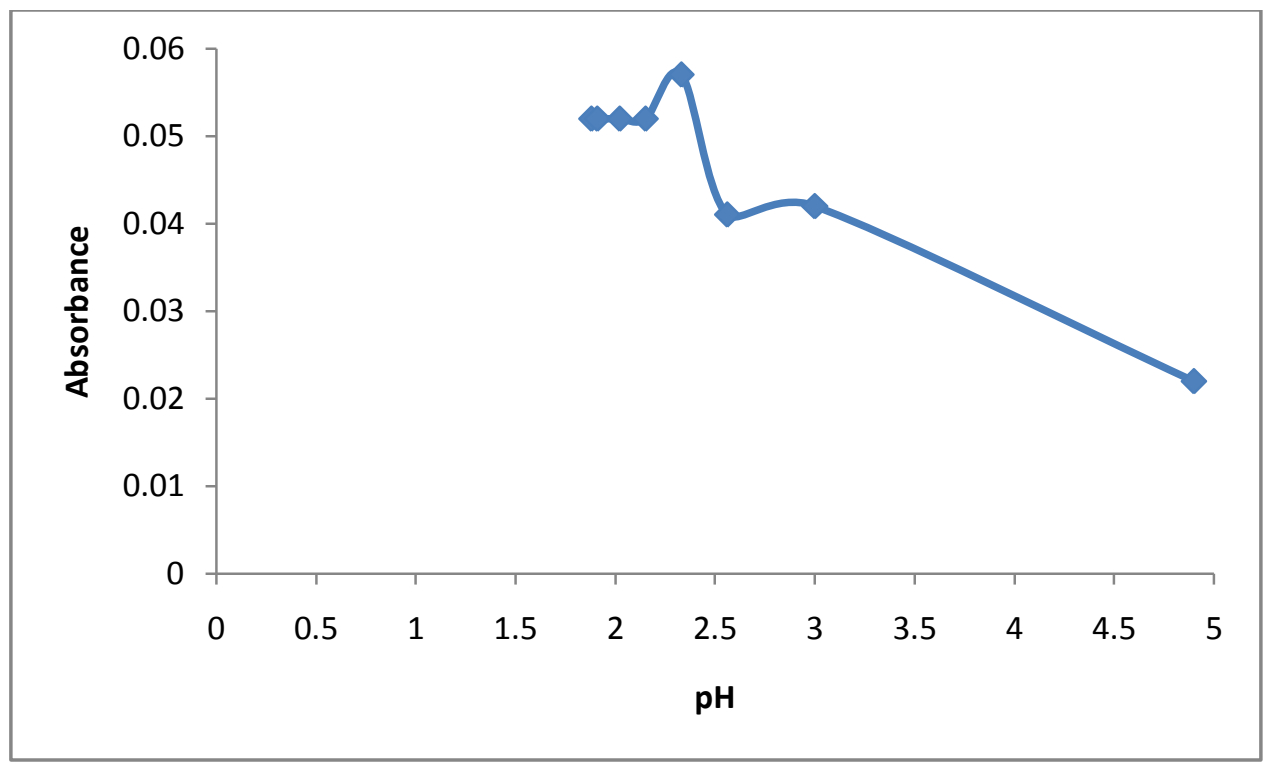

Figure 3 effect of $\mathrm{pH}$ variation on signal of $0.5 \mathrm{ppm} \mathrm{Pb}$.

\section{Effect of ligand Concentration}

The effect of concentration of APDC on the analytical responses was consequently studied. Therefore, a set of similar experiments under the conditions of $20 \mathrm{ppm} \mathrm{Pb}$ (II) ion, $1 \%$ (v/v)Triton $\mathrm{X}-114$, at $\mathrm{pH} 2.5$ and a different range of amounts of APDC was carried out (0-3)ml.It was observed that the absorbance increased by increasing the ligand volume. The sensitivity increases up to $2 \mathrm{ml}$ of the amount of APDC which reaches a plateau. At this amount, a volume of $2 \mathrm{ml}$ is selected as a suitable amount of APDC for the extraction process in order to make the extraction reaction complete (Figure 4).

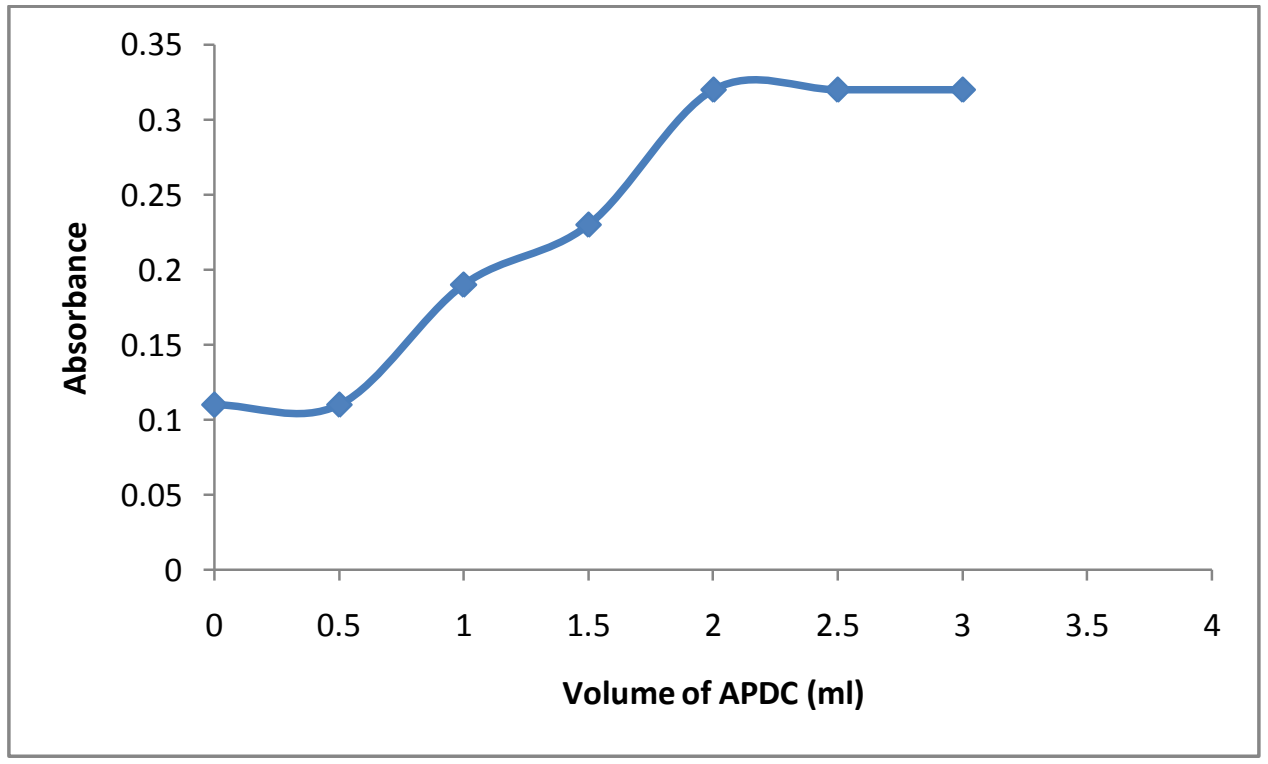

Figure 4 Effect of ligand concentrations on the atomic absorption signal of $20 \mathrm{ppm} \mathrm{Pb.}$

Effect of surfactant concentrations:-

A good cloud point extraction should maximize the extraction efficiency by minimizing the phase volume ratio (Vorg/Vaq), as a result improving the concentration factor. Triton X-114 was select for the formation of the surfactant rich phase due to its low cloud point temperature and industrial availability in a high purified uniform form, low toxicity and low cost and high density of the surfactant rich phase, which simplifies phase separation by centrifugation. Figure 5 shows the effect of Triton X-114 concentrations on the APDC preconcentration of lead. The 
signals of lead increased as the Triton X-114 concentration increased from 1\% (V/V) Triton X-114 concentration was prepared (0.1-3) $\mathrm{ml}$, the signals was increased by using $0.5 \mathrm{ml}$ and the maximum absorbance in the range (02)ml. Hence a low signal was decreased over $2 \mathrm{ml}$ from the surfactant. Therefore, $2 \mathrm{ml}$ of $1 \%$ (V/V) Triton $\mathrm{X}-114$ was employed for the rest of this work as shown in Figure 5.

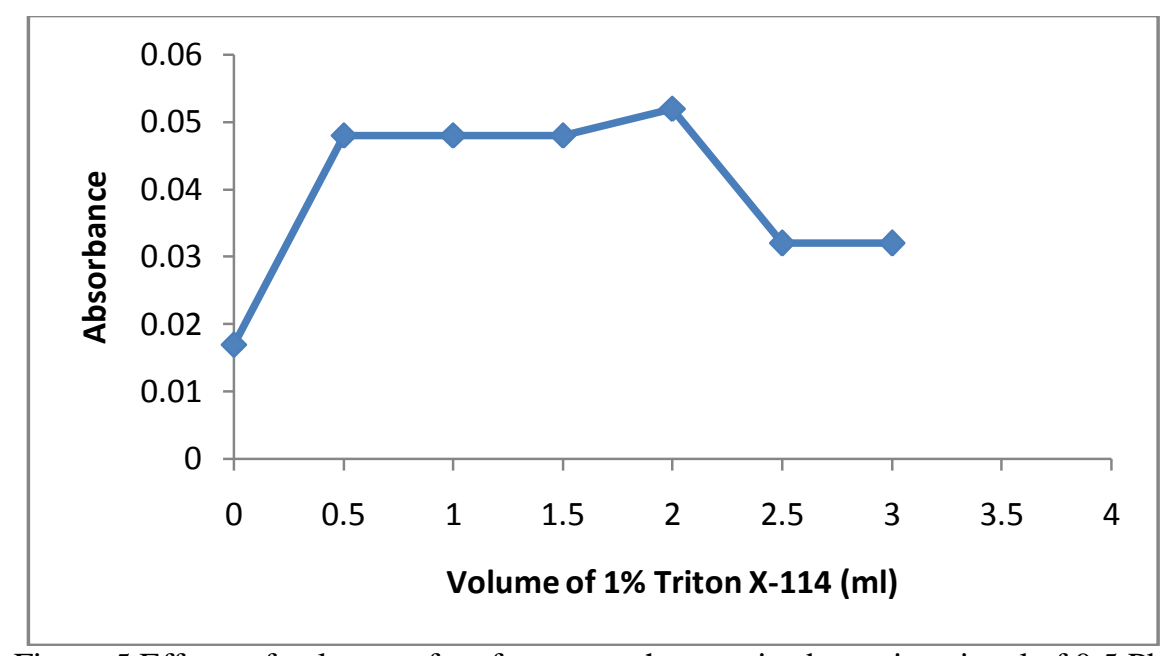

Figure 5 Effects of volumes of surfactant on the atomic absorption signal of $0.5 \mathrm{~Pb}$.

\section{Effects of the diluents agent for the surfactant -rich phase:-}

An organic solvent should be low viscosity, low surface tension and easily combustible in flame atomic absorption. Different solvents for the surfactant-rich phase were examined so as to select the one producing the optimal results regarding sensitivity. Acetone, methanol, ethanol water mixture (1:1) (Ethanol: $\left.\mathrm{HNO}_{3}\right)$ and DMF were tested for this purpose. Ethanol: $\mathrm{HNO}_{3}$ mixture dissolved completely the surfactants which in its extracted complex of lead -APDC complex and the best recovery were obtained and an optimum volume is $0.5 \mathrm{ml}$. For more enhancement of the signal, on other hand the use of $0.5 \mathrm{ml}$ of $(1 \mathrm{~N})$ nitric acid was added in order to release the $\mathrm{Pb}$ (II) from the complex (Figure 6.)

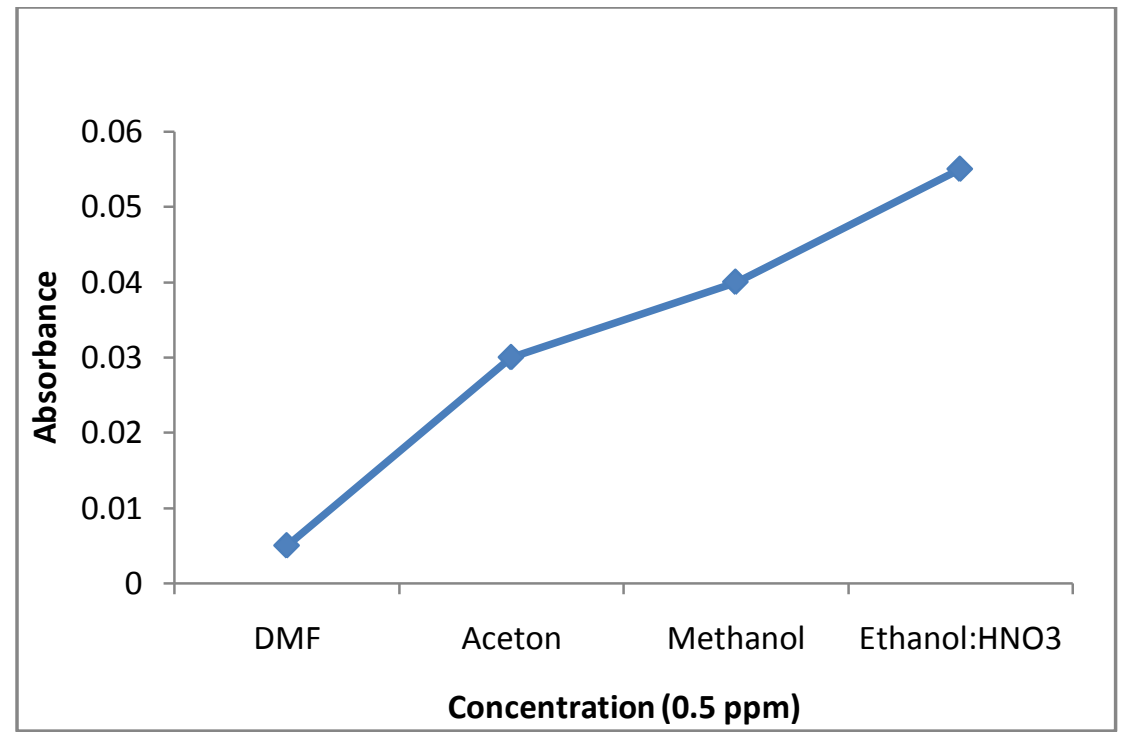

Figure 6 Effect of different diluent agent concentration.

\section{Effect of Temperature:-}

Cloud point formation obey to thermodynamic law with Optimum Temperature extraction performed with temperature ranging from $25 \mathrm{C}^{\circ}$ to $55 \mathrm{C}^{\circ}$ Shows $45 \mathrm{C}^{\circ}$ was suitable for Cloud point formation with higher viscosity and easily separated for $\mathrm{Pb}^{+2}$-complex ion at lower temperature the separation of two phases is not complete. At 
Higher temperature the decomposition of ion complex and reduction of extraction and micelles formation is happened.

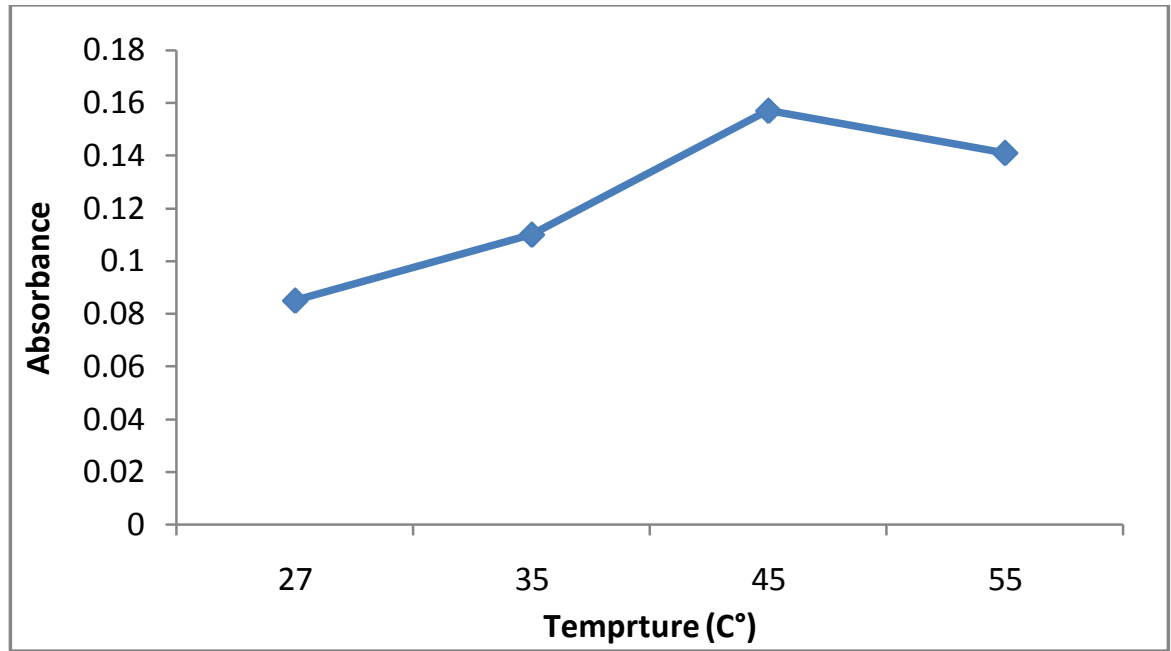

Figure 7 Study the effect of temperature.

\section{Determination of lead in different water samples:-}

In order to test the reliability of the proposed methodology suitable for the assaying of lead in different water samples. For this purpose, $1 \mathrm{ml}$ of each of the samples were taken with APDC $2 \mathrm{ml}$ concentration of $200 \mathrm{ppm}$ a $2 \mathrm{ml}$ $1 \%(\mathrm{v} / \mathrm{v})$ Triton $\mathrm{X}-114$ and, following the proposed procedure. The results show that the sample water from Southren Shat al arab with salinity $2.7 \mathrm{ppt}$ gave a recovery percentage ranging from $96 \%$ to $102 \%$ whereas water samples from Faw has a salinity of $31 \mathrm{ppt}$ and gave a recovery percentage ranging from $97 \%$ to $102 \%$ these results shows a affective proposal method for determination of $\mathrm{Pb}$ in salinity matrix sample. Although the salinity of waste water is only $3.3 \mathrm{ppt}$, the recovery percentage was an enhancement matrix $(107 \%)$ due to the presence of organic compounds. The recovery percentage varies form $100.2 \%$ to $102 \%$. The water samples of RO3(reverse osmosis water treatment system) has a salinity 9.4 of and recovery percentage ranging from $100 \%$ to $103 \%$. In total the methodology was satisfying for the determination of lead recovery by using mixed modifier, by direct modification as well as standard addition method fig(5).

Table 1 Recovery percentage of the matrix modified procedure of real environment samples.

\begin{tabular}{|c|c|c|c|c|c|c|}
\hline Sample & $\begin{array}{c}\text { Pb Content } \\
\mu \mathrm{g} / \mathrm{L}\end{array}$ & $\begin{array}{c}\mathrm{Pb} \text { add } \\
\mu \mathrm{g}\end{array}$ & $\begin{array}{c}\mathrm{Pb} \text { Found } \\
\mu \mathrm{g} / \mathrm{L}\end{array}$ & Recovery \% & Error\% & Mean recovery\% \\
\hline \multirow{4}{*}{$\begin{array}{c}\text { Southren } \\
\text { Shat al } \\
\text { arab }\end{array}$} & 243.5 & 2000 & 23.13 .9 & 96 & -4 & \multirow[t]{4}{*}{$99.6 \pm 0.4$} \\
\hline & & & & & & \\
\hline & 243.5 & 6000 & 6211.18 & 100.5 & 0.5 & \\
\hline & 243.5 & 8000 & 8037.997 & 102.5 & 2.5 & \\
\hline \multirow[t]{3}{*}{ Faw } & 114.4741 & 2000 & 2068.539 & 102.2206 & 2.22 & \multirow[t]{3}{*}{$100.298 \pm 0.297$} \\
\hline & 114.4741 & 4000 & 4213.166 & 97.65753 & -2.45 & \\
\hline & 114.4741 & 6000 & 6052.969 & 101.0161 & 1.01 & \\
\hline \multirow{4}{*}{$\begin{array}{c}\text { Waste } \\
\text { water* }\end{array}$} & & & & & & \multirow[t]{4}{*}{$104.854 \pm 4.854$} \\
\hline & 492.88 & 4000 & 4473.899 & 100.4243 & 0.4243 & \\
\hline & 492.88 & 6000 & 6066.304 & 107.0319 & 7.031 & \\
\hline & 492.88 & 8000 & 7927.356 & 107.1338 & 7.133 & \\
\hline \multirow[t]{3}{*}{ RO3** } & 281.644 & 2000 & 2274.864 & 100.298 & 0.298 & \multirow[t]{3}{*}{$101.657 \pm 1.657$} \\
\hline & 281.644 & 6000 & 6066.305 & 103.5498 & 3.5498 & \\
\hline & 281.644 & 8000 & 8189.511 & 101.125 & 1.125 & \\
\hline
\end{tabular}




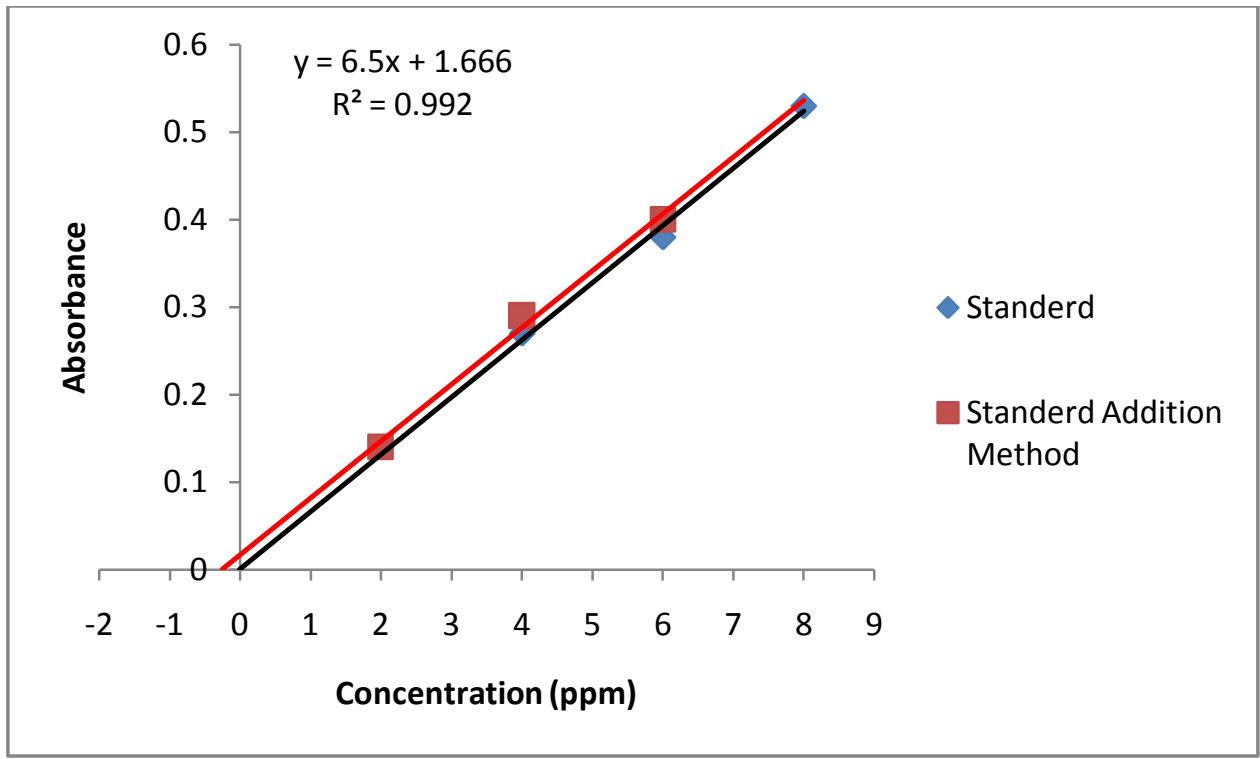

Figure 8 Standard Addition Method for determination $\mathrm{Pb}$ in FAW Sample

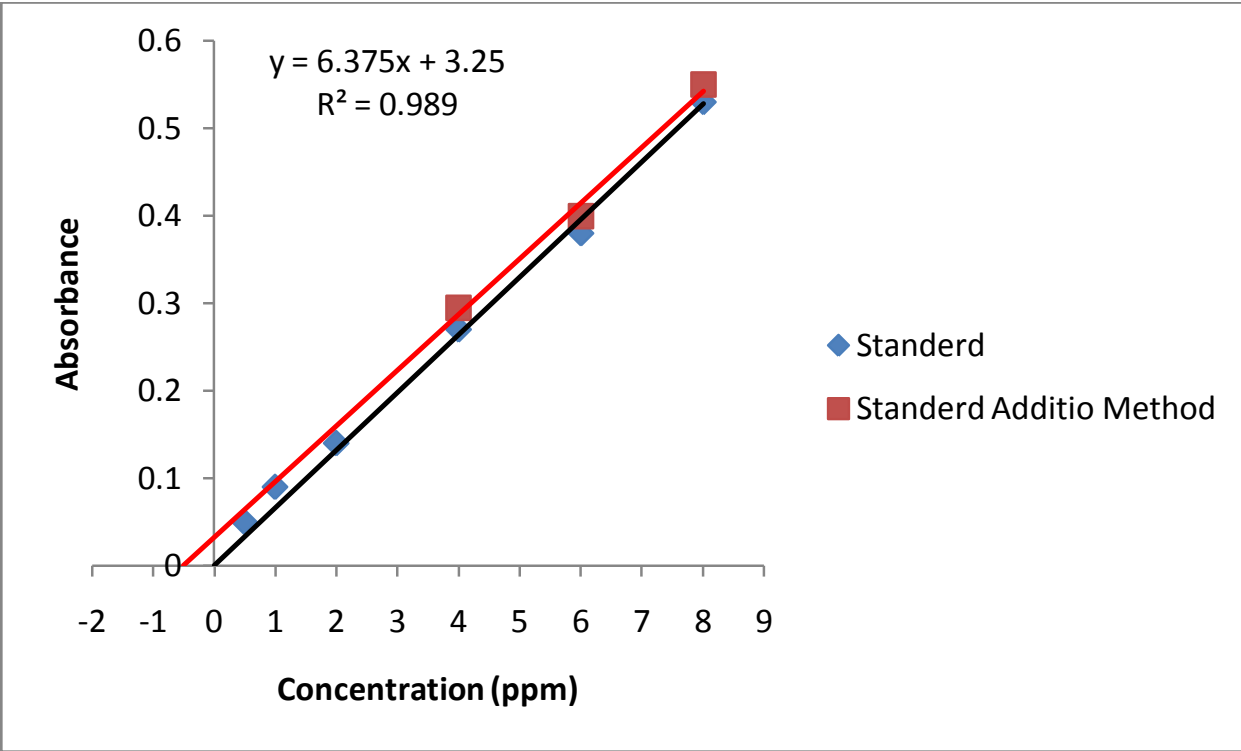

Figure 9 Standard additions method and recovery calculation for waste water Sample 


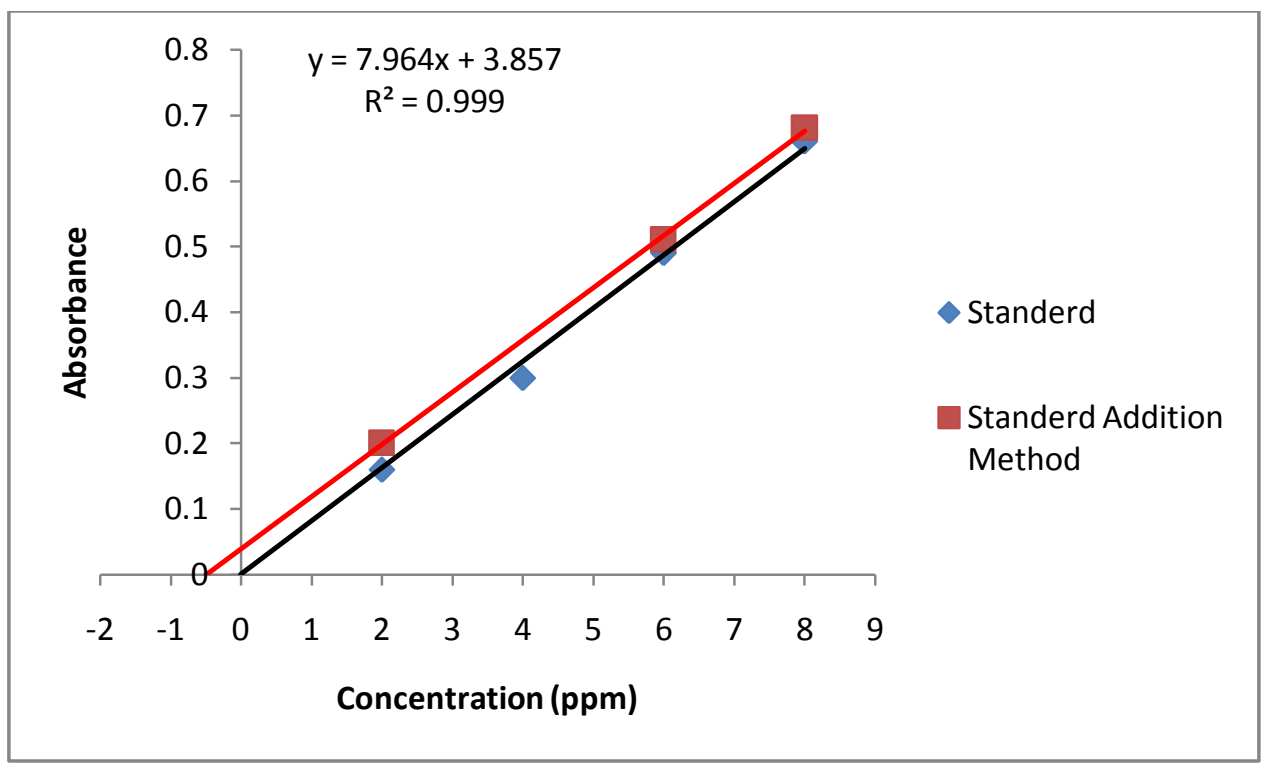

Figure 10 Standard eddition method recovery calculation for Southern shatt al Arab Sample (seba)

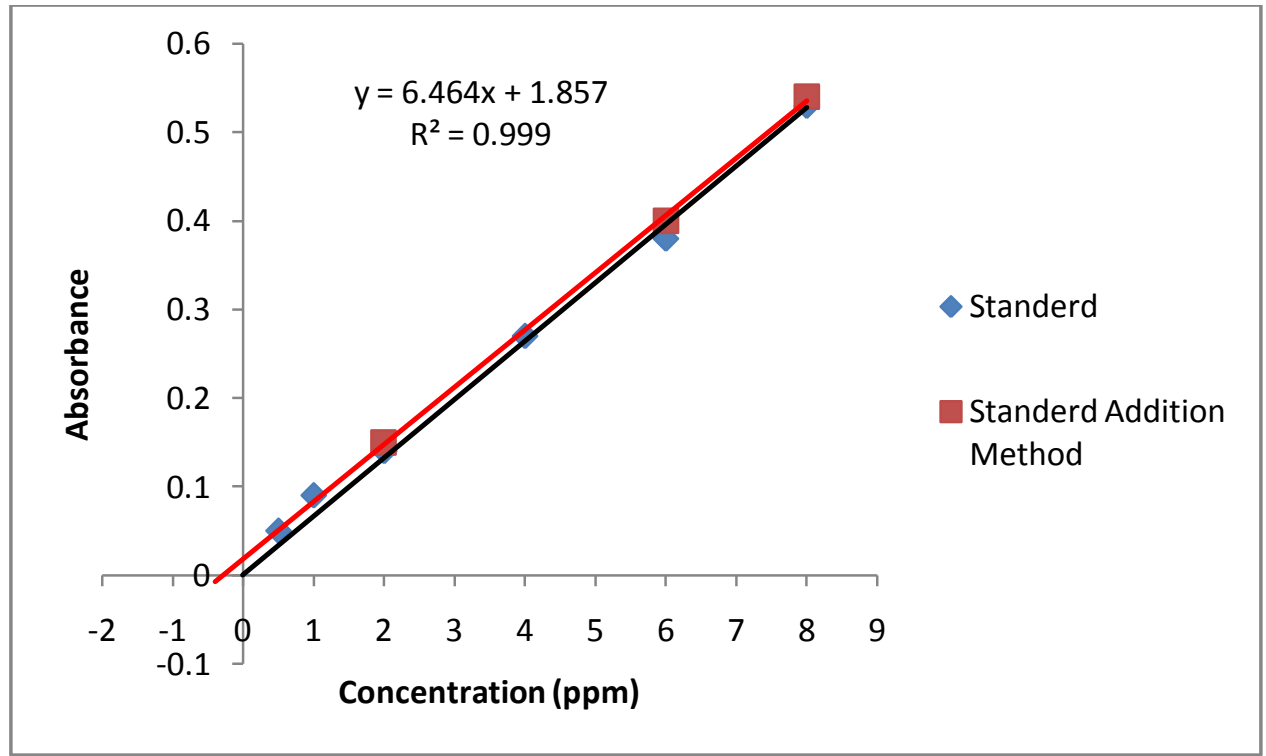

Figure 11 Standard Addition Method for determination $\mathrm{Pb}$ in rejection RO plant Sample

\section{Analytical performance:-}

Under the optimum conditions, performance characteristics were obtained by processing standard solutions of $\mathrm{Pb}$ (II) and the data is illustrated in Table1. Calibration functions were linear at least up to $20 \mu \mathrm{g} \mathrm{ml}^{-1}, 0.5 \mu \mathrm{g} \mathrm{ml}^{-1}$. Figure (7)shows this results. Furthermore, for preconcentration of $1 \mathrm{ml}$ of the working standard solutions based on the slope ratio of calibration curves with and without preconcentration, an enrichment factor of 3.8, was obtained for $\mathrm{Pb}$ (II). To test the reproducibility of the proposed extraction method, the suggested procedure was repeated eight times under optimum conditions. The relative standard deviation (R.S.D.) was measured to be $1.31 \%$, for $\mathrm{Pb}$. 


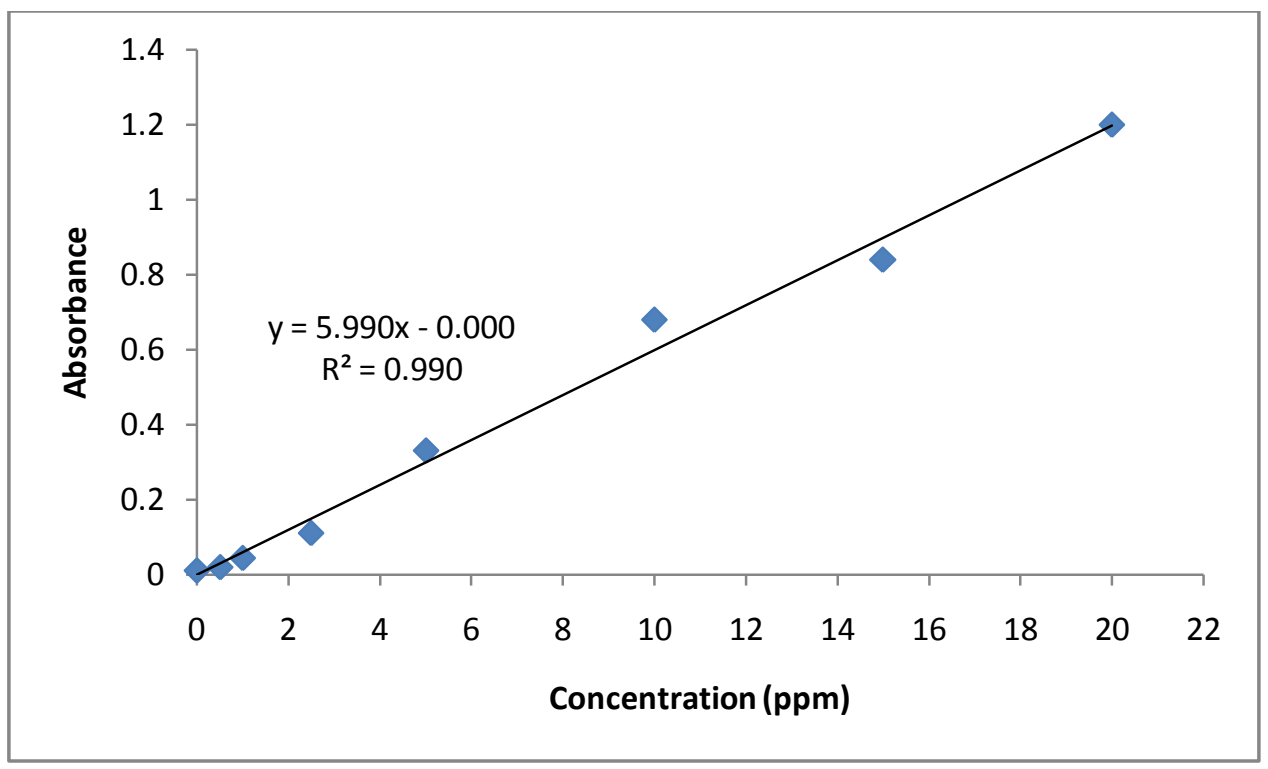

Figure 12 Calibration Curve

Cloud point extraction is asensitive, inexpensive, simple, and rapid system in preconcentration and separation of trace metal. TritonX-114 is used as cloud point extractant because it has the low cloud point temperature and high density, and, more importantly, it is very economical. In the $\mathrm{pH} 2.5, \mathrm{~Pb}$ (II) and APDC can form stable complexation. After extraction preconcentration by neutral surface active agents Triton $\mathrm{X} 114$, the element $\mathrm{Pb}$ can be measured to the level of $0.5 \mu \mathrm{gmL}^{-1}$ which is very satisfactory.

\section{References:-}

1. Manahan, S.E., Environmental chemistry, . , 2002.

2. E., B., Toxic Metals and Their Analysis, . 1990.

3. Barin J S, B.F.R., Dressler V L, Microwaveinduced combustion coupled to flame furnace atomic absorption spectrometry for determination of cadmium and lead in botanical samples, . Analytical Chemistry, 2008. 80:23: p., , ,9369-9374.

4. Ajtony Z., S.N., Susko E. K.,, Direct sample introduction of wines in graphite furnace atomic absorption spectrometry for the simultaneous determination of arsenic, cadmium, copper and lead content, ,, ,. Talanta, 2008. 76:3: p. 627-634.

5. Koksal J., S.V., Janos P., . Talanta, , 2002,. 58:325.

6. Chen J., T.K.C., Determination of cobalt and nickel in water samples by flame atomic absorption spectrometry after cloud point extraction,.. Anal.Chim. Acta, , 2001. 434: p. 325-330.

7. E. K. Paleologos, D.L.G., and M. I. Karayannis,, "Micellemediated separation and cloud-point extraction,". Trends in Analytical Chemistry, , 2005. vol. 24, (no. 5, ): p. pp. 426-436,.

8. M. J. Rosen, Surfactants and Interfacial Phenomena, . 1987.

9. M. de Almeida Bezerra, M.A.Z.A., and S. L. C. and Ferreira, "Cloud point extraction as a procedure of separation and preconcentration for metal determination using spectroanalytical techniques: . a review,"Applied Spectroscopy Reviews,, 2005. vol. 40,(no. 4, ): p. pp. 269-299,.

10. A. Shokrollahi, M.G., O. Hossaini, N. Khanjari, and M. and Soylak, "Cloud point extraction and ame atomic absorption spectrometry combination for copper(II) ion in environmental and biological samples,.. "Journal of Hazardous Materials, , 2008. vol. 160,(no. 2-3): p. pp. 435-440,.

11. M. Ghaedi, A.S., R. Mehrnoosh, O. Hossaini, and and M. Soylak, "Combination of cloud point extraction and ame atomic absorption spectrometry for preconcentration and determination of trace iron in environmental and biological samples, "Central European Journal of Chemistry,, 2008. vol. 6, no. 3,: p. pp. 488-496,.

12. Shokrollahi A., G.M., Hosseini O.,, Cloud point extraction and flame atomic absorption spectrometry combination for copper (II) ion in environmental and biological samples, , . J of Hazardous Materials,, 2008. 160:(2-3,): p. 435-440. 
13. Ali Niazia, b., Tahereh Momeni-Isfahania, and Z. Ahmaria, Spectrophotometric determination of mercury in water samples after cloud point extraction using nonionic surfactant Triton X-114. Journal of Hazardous Materials June 2009. Volume 165,( Issues 1-3, 15): p. Pages 1200-1203.

14. Wua, P., et al., Cloud point extraction-thermospray flame quartz furnace atomic absorption spectrometry for determination of ultratrace cadmium in water and urine. Spectrochimica Acta Part B: Atomic Spectroscopy, December 2006. Volume 61, (Issue 12): p. Pages 1310-1314.

15. M. F. Giné, A.F.P., E. L. Silva, J. E. S. Sarkis, and M. H. and Kakazu, "Sequential cloud point extraction of trace elements from biological samples and determination by inductively coupled plasma mass spectrometry, ”. JournaloftheBrazilian Chemical Society,.. 2008. vol. 19,( no. 3): p. pp. 471-477,

16. V. A. Lemos, P.X.B., and J. S. Santos, "Me-BTABr reagentin cloud point extraction for spectrometric determination of copper in water samples,, . "Journal of the Brazilian Chemical Society, 2006. vol. 17 (no. 1): p. pp. 30-35. 